\title{
THE TETRAGONODERUS GROUP OF CHLAENIUS (COLEOPTERA: CARABIDAE) IN THE INDO-AUSTRALIAN ARCHIPELAGO
}

\author{
By P. J. Darlington, Jr. \\ Museum of Comparative Zoology
}

The two new Chlaenius here described belong to a zoogeographically interesting group of the genus characterized by exceptionally short, subtransverse mandibles. The group may be called the Chlaenius tetragonoderus group. C. tetragonoderus Chaudoir itself oscurs from the southeastern corner of Asia (Burma) to Celebes and the Philippines, with subspecies in the Moluccas (Louwerens 1956) and the Palau Islands (Darlington 1970); it is recorded also from Timor (Louwerens 1953). The group is represented in New Guinea and northeastern Australia by maculiger Castelnau (Darlington $1968,2-5)$, on the Mariana Is. in Micronesia by a very distinct endemic species (marianensis Darlington 1970), and on Timor and the Solomons by new species described below. It will be seen that the group has differentiated mainly in the Indo-Australian archipelago and western Pacific Islands. It is in fact the only group of the genus that has differentiated over so wide an area of the islands. Its success on islands may be due partly to its habitat. Many Chlaenius live in wet places, but tetragonoderus and maculiger (which I have collected in the Philippines and New Guinea respectively) and presumably the other species of the group apparently live away from water, on the ground in rain forest, and need not depend on finding permanent fresh water when they reach a new island.

Key to Chlaenius of tetragonoderus group

I. Elytra duller with intervals closely punctate with punctures of moderate size, the punctures not or not much sparser toward base of inner intervals; elytra often spotted

- Elytra more shining; elytral punctation either much sparser toward base of inner intervals or coarser (with pronotum more coarsely punctate too); elytra not spotted

2. Head and pronotum submetallic (greenish or bluish); legs usually pale; length $c$. IO-I $2 \mathrm{~mm}$ (3 subspecies) tetragonoderus

- Head and pronotum not metallic; legs dark 3

3. Prothorax narrow (width/length I.2I and I.22); pronotum closely punctate throughout; length $c$. $12 \mathrm{~mm}$ timorensis 
- Prothorax wider; pronotum with sparsely punctate areas near middle; length $c$. $12-14 \mathrm{~mm}$ maculiger

4. Elytral punctures of moderate size but sparser especially toward base of inner intervals; length I I.2-12.7 mm greensladei

- Elytral (and pronotal) punctures very coarse; length $c$. Io $\mathrm{mm}$ marianensis

\section{Chlaenius timorensis n. sp.}

Fig. I

Description. Form as in Fig. I, rather depressed; brownish-black, appendages dark; entire upper surface moderately punctate and with fine, moderately long pubescence, the punctation being closer on head; surface between punctures shining on head, faintly transversely microreticulate on pronotum, dull and heavily $c$. isodiametrically reticulate on elytra. Head 0.69 and 0.7 I width prothorax; mandibles short, subtransverse, very strongly arcuate; antennae with segments 3 and 4 subequal ( 3 slightly longer), pubescent from segment 4; mentum with large apically rounded tooth. Prothorax: width/length I.2I and I.22; base/apex I.28 and I.2O; lateral margins narrow, very weakly reflexed posteriorly, each with seta near base but none near middle; base with hair fringe, not margined; apex not distinctly margined; disc depressed, with middle line distinct, transverse impressions obsolete, baso-lateral impressions weak, sublinear, running into slight longitudinal impressions anteriorly; surface of disc nearly evenly punctate with rather close, nearly uniform punctures of moderate size. Elytra subparallel; width elytra/prothorax I.42 and I.43 (approximate); base margined, margins rounded at humeri; subapical marginal interruptions present; striae fine finely impressed, intervals slightly convex, finely multipunctate, the punctures not forming regular rows. Lower surface: prosternal process rounded, margined at sides but margin weak or interrupted at apex; much of lower surface including part of proepisterna rather finely punctate, but abdomen nearly smooth (with some sparse minute punctules at middle). Inner wings fully developed. Legs normal; 5th hindtarsal segments with $c$. 4 accessory setae each side below. Secondary sexual characters: $0^{\top}$ front tarsi rather widely dilated, with 2nd segments $c$. I/3 wider than long; $\sigma^{x}$ with I seta each side last ventral segment; + unknown. Measurements: length c. I2; width c. $4.6 \mathrm{~mm}$.

Types. Holotype $\sigma^{\pi}$ (British Mus.) and one broken $\sigma^{\pi}$ paratype (M. C. Z., Type No. 31,676) both from "Gng Leo," Timor, 20004000 ft. (c. 600-I200 m), Nov., Dec. (Doherty). 

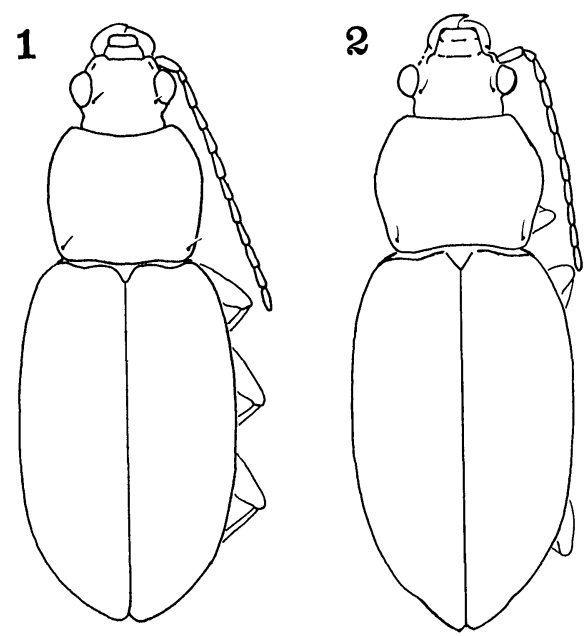

Fig. 1. Chlaenius timorensis n. sp., holotype.

Fig. 2. Chlaenius greensladei n. sp., holtoype.

Notes. The very short, subtransverse mandibles, as well as other characters of this insect, place it in the Chlaenius tetragonoderus group. The present new species differs from the others of the group as indicated in the preceding key.

\section{Chlaenius greensladei n. sp.}

Fig. 2

Description. Form as in Fig. 2, rather depressed; black, appendages dark; rather shining, pubescence very short, virtually obsolete except at sides of elytra; head with punctures fine, close, of mixed sizes; pronotum with punctures close and of mixed sizes laterally, slightly more sparse in areas near middle; elytra with punctures not dense, sparser on inner intervals anteriorly; reticulate microsculpture between punctures absent on head, fine and light on pronotum and elytra. Head 0.67 and 0.68 width prothorax; details $c$. as in preceding species (timorensis). Prothorax: width/length $\mathrm{I} .33$ and I.32; base/apex I.27 and I.23; other details $c$. as in preceding species (timorensis) except punctation of disc sparser especially near middle and punctures of mixed sizes. Elytra: width elytra/prothorax $\mathrm{I} .3 \mathrm{O}$ and $\mathrm{I} .3 \mathrm{I}$; striae deeper than in preceding (timorensis); intervals convex, irregularly rather sparsely punctate, the punctures sparser anteriorly on inner intervals. Lower surface: prosternal 
process rounded, weakly margined; much of lower surface (somewhat variably) punctate but abdomen with only sparse minute punctules at middle. Inner wings fully developed. Legs normal; 5th hind tarsal segments with $c .4$ accessory setae each side below. Secondary sexual characters: $\sigma^{\top}$ front tarsi rather widely dialated with 2nd segments nearly I/3 wider than long; $\sigma^{\pi}$ with $I$, 92 setae each side last ventral segment. Measurements: length II.2-I2.7; 4.3-4.7 $\mathrm{mm}$.

Types. Holotype $\sigma^{\top}$ (British Mus.) from Mt. Austen, Guadalcanal, Solomon Is., Aug. 15, 1966 (P. J. M. Greenslade), at $\mathrm{m}$ (ercury) v(apor) light, Field No. 21778; and paratypes as follows. One +, Kukum, Guadalcanal, Solomon Is., April 1965 (Greenslade), at m. v. light, Fïeld No. I678o (M. C. Z., Type No. 31,677); I $\sigma^{\pi}$ (U. S. N. M.), Bougainville, Solomon Is., Jan. I944 (A. B. Gurney); I (broken) ơ (M. C. Z.), Munda, New Georgia, Solomon Is., Feb. 1945 (L. A. Conwell).

Measured specimens. The $\sigma^{\pi}$ holotype and $q$ paratype from Guadalcanal.

Notes. The characters distinguishing this species from other members of the tetragonoderus group of Chlaenius are given in the preceding key. The present species differs also in having exceptionally short dorsal pubescence.

\section{REFERENCES}

Darlington, P. J., JR.

1968. The carabid beetles of New Guinea. Part III. Harpalinae (continued): Perigonini to Pseudomorphini. Bull. Mus. Comp. Zool. 137 (1) : 1-253.

1970. Coleoptera: Carabidae including Cicindelinae. Insects of Micronesia $15(1): 1-50$.

LOUWERENS, C. J.

1953. Verh. Naturf. Ges. Basel 64(2): 311.

1956. Treubia $23(2): 234$. 

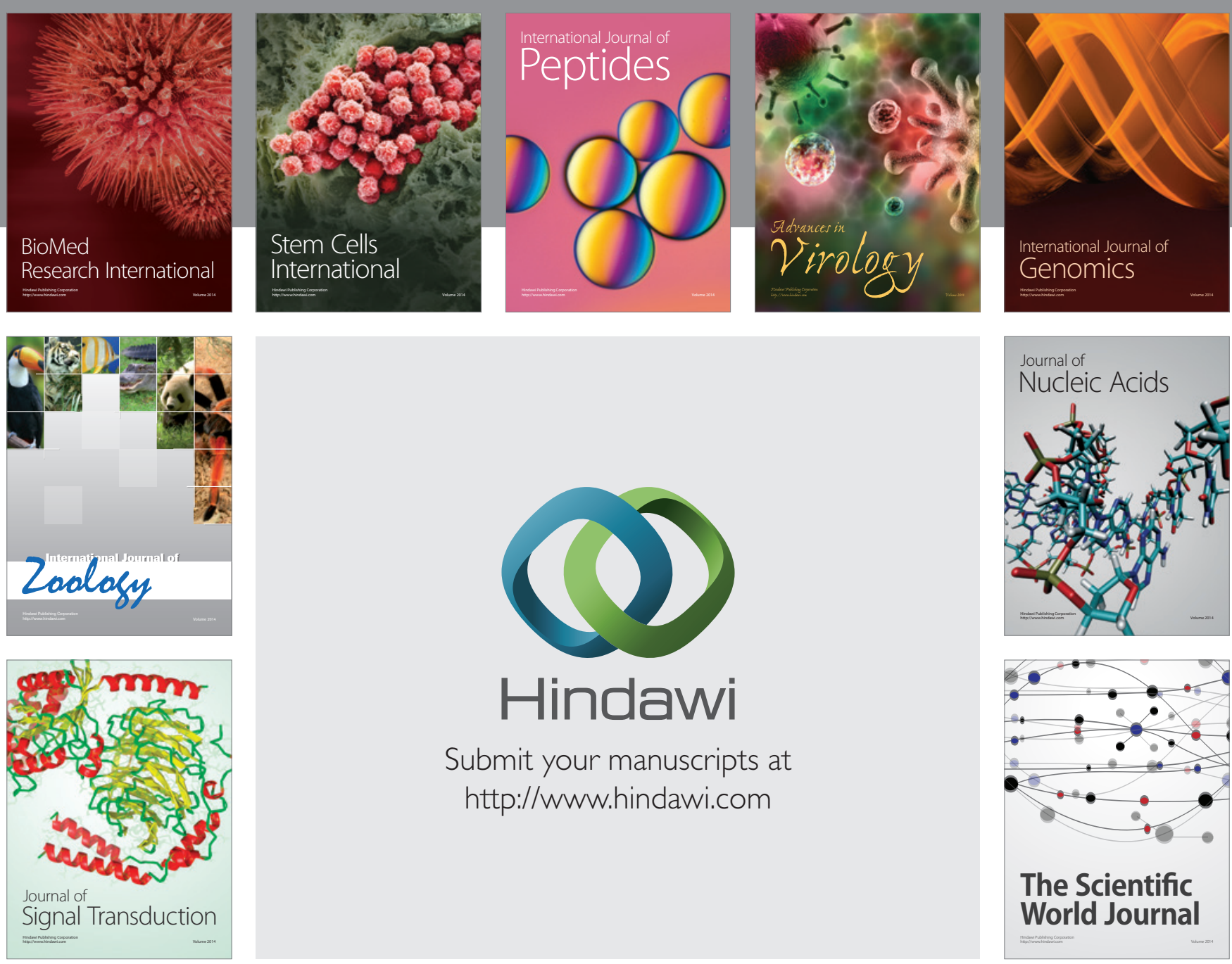

Submit your manuscripts at

http://www.hindawi.com
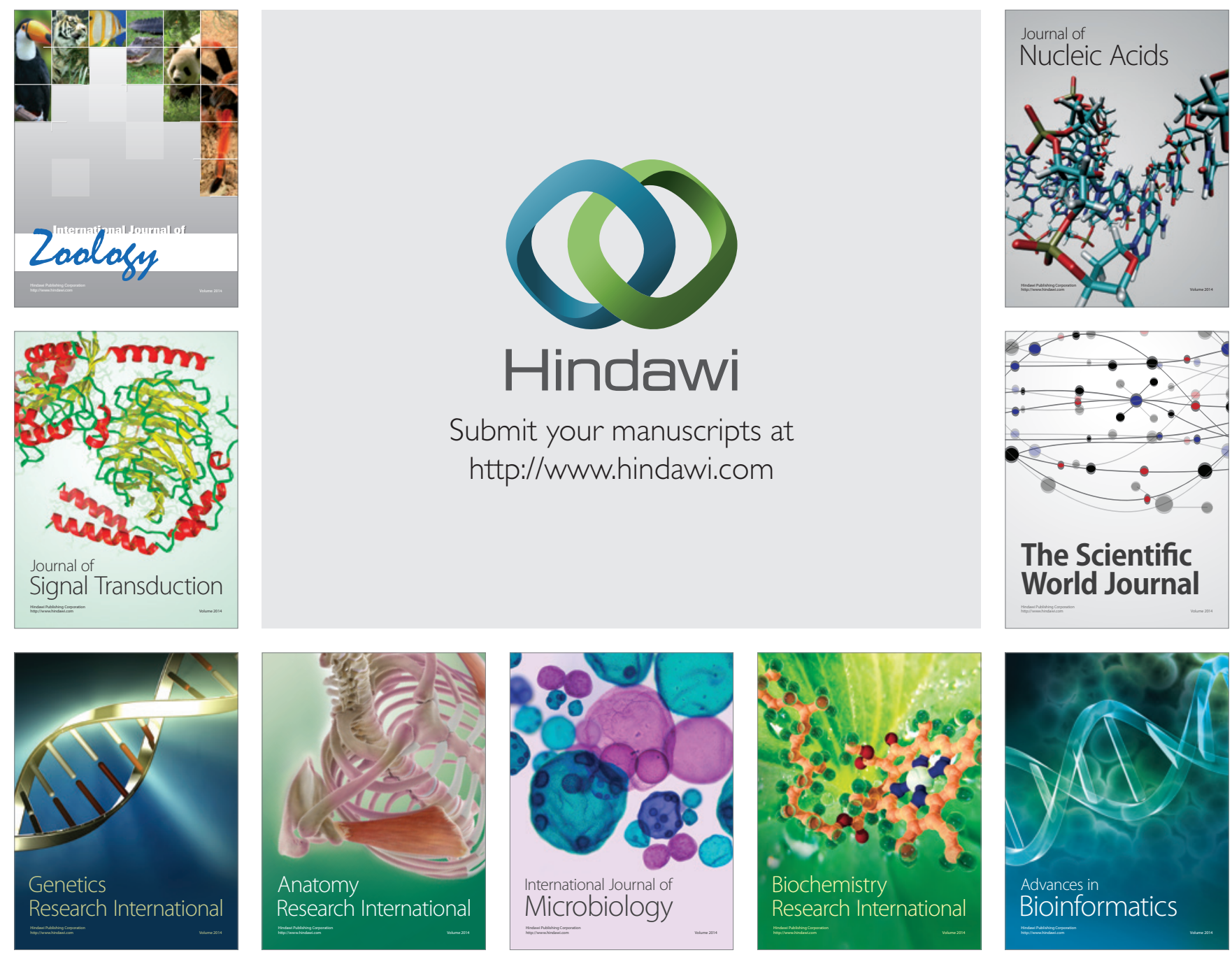

The Scientific World Journal
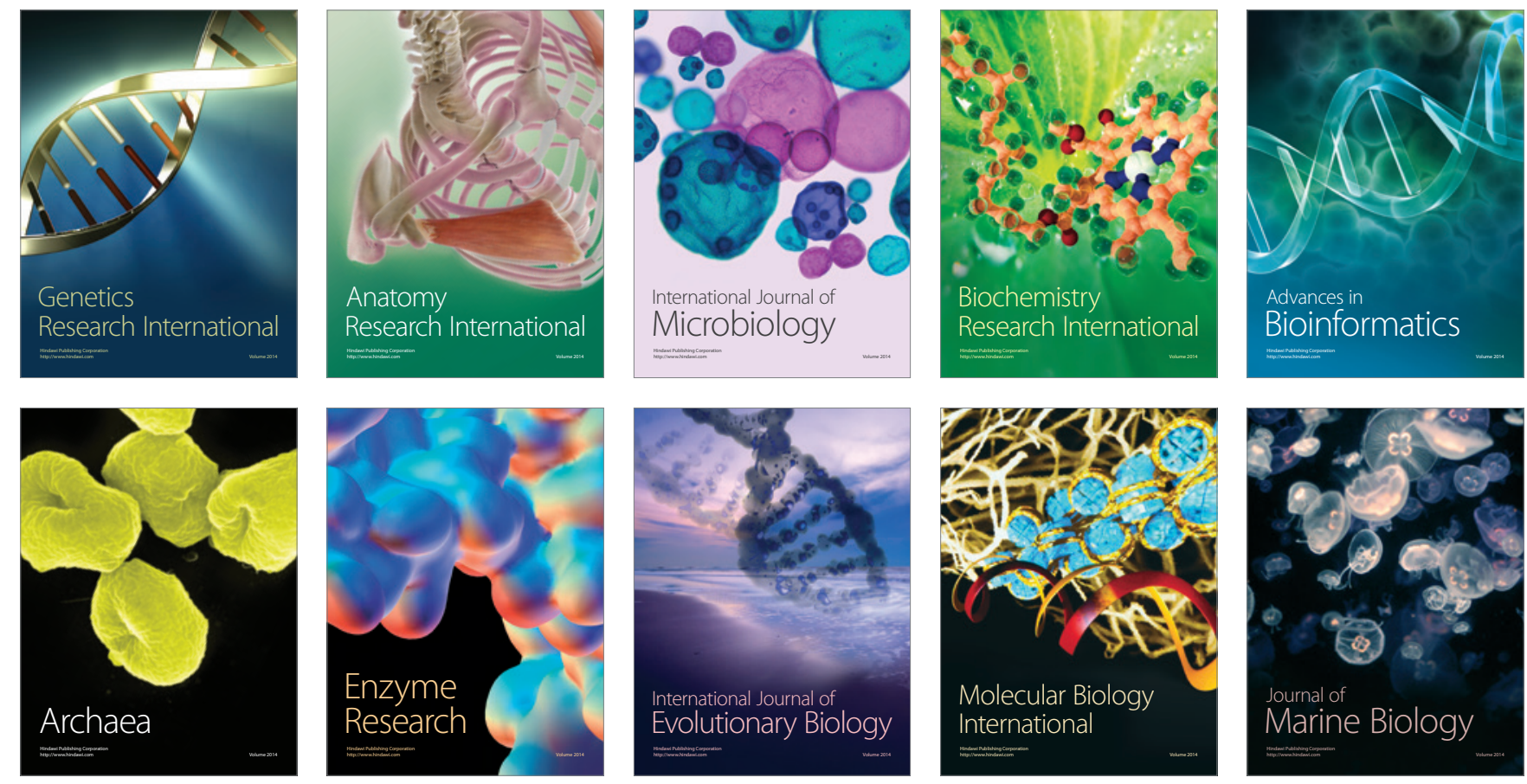